\title{
Reaching the Colorectal Liver Masses
}

\author{
David Sindram, MD, $\mathbf{P h D}^{1,2}$ \\ ${ }^{1}$ Division of Hepatobiliary Surgery, Department of General Surgery, Carolinas Medical Center, Charlotte, NC; ${ }^{2}$ Division of \\ Gastrointestinal and Minimally Invasive Surgery, Department of General Surgery, Carolinas Medical Center, Charlotte, \\ $\mathrm{NC}$
}

For most of our medical and surgical colleagues, the mere suggestion of liver surgery invokes images of yellow patients on ventilators who just barely escaped the jaws of the surgical vise and are lucky to be able to live and tell their story. Only the young and the physically strong are considered viable candidates for such a brutally heroic effort to (just) stall their cancer, and then only if they truly desire to go forward. In the minds of many, still, the balance between surviving the operation and the cancer is estimated to be a tight equilibrium. On top of that, there is a prevailing sense of having to protect these emotionally and physically friable patients from the hands of such aggressive surgeons. The modern truth could not be farther removed from these perceptions. Liver surgery has seen tremendous advances in the last decade, but some or most of these advances have hardly penetrated the medical and surgical community. Minimally invasive liver surgery, modern anesthesia techniques, novel stapler technologies, and energy devices have made liver surgery what it is nowadays: a safe and well-tolerated surgical modality with low morbidity and mortality. Complications still occur, needless to say, but with mortality rates of $1-2 \%$ in most modern series and less than $15 \%$ major morbidity, the horror images of times-gone-by hardly seem justified. ${ }^{1,2}$

The stages of colorectal cancer are based on the natural history of this disease, with stage IV disease identified as metastatic colorectal cancer. Without question, stage IV colorectal cancer carries a worse prognosis than stage III, II, or I. The natural history of stage IV colorectal cancer is dismal. However, the recognition that patients with

(C) Society of Surgical Oncology 2010

First Received: 29 June 2010;

Published Online: 14 September 2010

D. Sindram, $\mathrm{MD}, \mathrm{PhD}$

e-mail: David.Sindram@carolinashealthcare.org metastatic disease may benefit greatly from resection, including liver only, lung only and even combinations of liver and lung metastases, and oligo-metastatic extrahepatic disease, has tremendously increased the overall survival of this category of stage IV colorectal cancer patients. ${ }^{3-6}$ This has not been a subtle effect; 5- and 10year survival of 50-60\% and 20-30\% are being reported, in contrast to $0-3 \%$ 5-year survival if left untreated. ${ }^{4,7}$ These phenomenal results are not just attributable to surgery, but are the result of a multimodality approach and due to advances in chemotherapy and percutaneous interventions as well. It is hardly disputed, though, that by far the largest contribution to overall survival has been made by surgical resection where feasible.

Within the hepatobiliary community, these advances are well recognized and have resulted in broad recommendations for surgical management of colorectal liver metastases. ${ }^{6}$ Within our highly specialized community, intense debates are raging based on the latest data and opinions regarding the validity of resection of multiple lesions in the presence of extrahepatic disease, strategies involving portal vein embolization and staged resections, as well as on ablation and resection or ablation as a primary modality. The real focus of our continued efforts, and the overall consensus, although clearly stated in our literature, may be obscured to the referring physicians counseling their patients in their offices. In fact, the debates and opinions flaring in the journals and at symposia may perpetuate to some degree the impression of bloody horror shows from which patients ought to be protected.

The article by Ksienski et al. in this issue provides a rare opportunity to gain further insight into the decision-making process. All new colorectal cancer cases referred to 5 cancer centers providing comprehensive cancer care were pooled and analyzed in a prospectively maintained database. All metastatic colorectal cases were reviewed, and 
charts were analyzed in a systematic fashion, in order to extract the decision-making process. Only $7 \%$ of patients (99 of 1335) with liver-only metastatic disease underwent surgery. Also, 64 patients with low tumor burden and good performance status were never even referred for surgical consultation. Of the patients that were seen by a hepatobiliary surgeon (a shocking 148 of 1335 patients), one-third did not undergo resection or ablation. After chart review of the nonreferred patients, it became clear that the most prominent reasons for nonreferral were "advanced" age (mean 68 vs. 62 in the referred group), multiplicity and/or multicentricity of tumors and fear of surgical morbidity. The most impressive findings of their investigations are summarized by the overall survival percentages. Overall median survival of patients who were referred but not resected was 1.83 years (3-year survival of $21.1 \%$ ). The median survival of patients who were not referred was 0.99 years (3-year survival of $8.6 \%$ ). When referral resulted in resection, median survival increased to 3.85 years (60.9\% 3-year survival).

Several confounders are appropriately pointed out in the study, but the overall validity remains. The simple act of referral to hepatobiliary surgeons and allowing them to weigh in with their expertise (and be mindful that this is in the era prior to the SSO/AHPBA joint statement loosening the criteria for resection and thus represents stringent selection of appropriate patients by hepatobiliary surgeons as well) resulted in a doubling (!) of median survival, even in absence of actual resection. This may of course be a reflection of the correct application of the eyeball test by the nonreferring doctors and thus skewing the data to the advantage of hepatobiliary surgeons, but this did not pan out in single and multivariate analysis in this study. On top of that, those patients who were resected benefited tremendously from the procedure, as measured by overall survival. These findings form a compelling argument to urge for less stringent referral criteria, most certainly in the current era of even less stringent resection criteria.
Data like this is hard to come by and demonstrates the importance of multicenter population based prospective database research. It allows for demonstration of the important positive impact of liver surgery on survival and may reveal large portions of patients who are denied appropriate surgical consultation. The follow-up with a thorough chart review in this study has been enlightening and identified that referring doctors refrain from referrals based on incorrect preconceived notions about the options available to liver surgeons. Letting referring doctors make the decisions regarding resectability and surgical intervention is not correct in this day and age of superspecialization. It is our obligation as liver surgeons, however, to get that message out.

\section{REFERENCES}

1. Nguyen KT, Gamblin TC, Geller DA. World review of laparoscopic liver resection-2,804 patients. Ann Surg. 2009;250: 831-41.

2. House MG, Ito H, Gonen M, Fong Y, Allen PJ, DeMatteo RP, et al. Survival after hepatic resection for metastatic colorectal cancer: trends in outcomes for 1,600 patients during two decades at a single institution. J Am Coll Surg. 2010;210:744-52, 752-5.

3. Marudanayagam R, Ramkumar K, Shanmugam V, Langman G, Rajesh P, Coldham C, et al. Long-term outcome after sequential resections of liver and lung metastases from colorectal carcinoma. HPB (Oxford). 2009;11:671-6.

4. Pawlik TM, Schulick RD, Choti MA. Expanding criteria for resectability of colorectal liver metastases. Oncologist. 2008;13: 51-64.

5. Yedibela S, Klein P, Feuchter K, Hoffmann M, Meyer T, Papadopoulos T, et al. Surgical management of pulmonary metastases from colorectal cancer in 153 patients. Ann Surg Oncol. 2006;13:1538-44.

6. Vauthey JN, Choti MA, Helton WS. AHPBA/SSO/SSAT Consensus Conference on hepatic colorectal metastases: rationale and overview of the conference. January 25, 2006. Ann Surg Oncol. 2006;13:1259-60.

7. Scheele J, Stangl R, Altendorf-Hofmann A. Hepatic metastases from colorectal carcinoma: impact of surgical resection on the natural history. Br J Surg. 1990;77:1241-6. 